\title{
Research on Application of Self-media Platform in College Enrollment Publicity in the New Period
}

\author{
Dan Zhang* Suxia Deng Xiang Li \\ Panjin Vocational and Technical College, Panjin, Liaoning, 124000, China
}

\section{ARTICLE INFO}

Article history

Revised: 18 September 2020

Accepted: 9 October 2020

Published Online: 16 October 2020

Keywords:

Universities

Enrollment publicity

Self-media platform

Application
Received: 11 September 2020

\begin{abstract}
Since the arrival of the media era, colleges and universities have undergone many new changes in enrollment, especially in the recruitment publicity work, self-media platform plays an important role. But for now, there are some problems in the application of self-media in college enrollment propaganda, for example, the promotion and management level of the platform needs to be improved, and the low quality of platform push content seriously affects the application effect of self-media. This paper aims at the problems existing in the application of self-media platform in the college enrollment propaganda, and formulates the effective solution strategy of the department, constantly improve the application effect of self-media platform in college enrollment propaganda.
\end{abstract}

licity work.

\section{The Important Value of Self-media Platform in College Enrollment Publicity}

nology, Since the emergence and development of the media, and play a great role in the development of various industries. The application of self-media platform in the process of college enrollment propaganda has effectively improved the quality and efficiency of propaganda. It reduces the cost of publicity, especially in the application of self-media platforms such as Weibo and WeChat, can make it easier for young people to accept and receive this information. At the same time in the media era, the communication and communication of propaganda content has become more efficient, colleges and universities can collect feedback from students, constantly optimize the content of publicity, Improve the quality of publicity to ensure the orderly conduct of college enrollment pub-
In the traditional college admissions campaign, Enrollment special issue and recruit students website application more, but in the society rapid development, These methods can no longer meet the needs of students, it is difficult to timely information、 Full presentation to students. In the new era, young people have widely used self-media such as Weibo and WeChat, and in the reception and dissemination of information, also mainly rely on these self-media platforms. Therefore, colleges and universities in the recruitment and publicity work must change the propaganda strategy in time, actively introduce from the media platform, so that propaganda work more efficient ${ }^{[1]}$.

*Corresponding Author:

Dan Zhang,

Correspondence address: Panjin Vocational and Technical College, Panjin City, Liaoning Province, 124000, China;

E-mail:308164675@qq.com. 
First, compared to the traditional way of recruiting, the application of self-media platform not only has the information dissemination speed fast Low-cost features, also has the traditional propaganda pattern not to achieve the high benefit. Under the application of self-media propaganda platform, colleges and universities can adjust the propaganda strategy in time to the current hot spots, present attractive promotional content for students. At the same time, it can communicate effectively with students, understand students' needs and preferences, and improve the quality and efficiency of college enrollment publici$\operatorname{ty}^{[2]}$. Second, the current dissemination of information is fragmented, and many students are scattered, But since the media can better solve the problem, Students from different regions, Can be free from time and space, Anytime and anywhere to understand the college enrollment publicity copy. At present, the application of Weibo, WeChat and other self-media in college enrollment propaganda is becoming more and more common, It plays an important role in improving the quality and efficiency of enrollment publicity, And colleges and universities keep pace with the times, effective means to achieve propaganda innovation. The application of self-media in college enrollment publicity, Is the necessity of the times, but also the direct result of students' diverse needs, So colleges must keep up with the times, Constantly optimize promotional push content, To provide a real, comprehensive and timely content for the broad audience, and truly play the role of self-media platform in the recruitment and publicity work $^{[3]}$.

\section{Problems in Application of Self-Media Platform}

Although colleges and universities continue to keep pace with the times in enrollment publicity work, Increasing the use of self-media, but there are still some problems in use, the existence of these problems makes the use of self-media platform greatly reduced. So, there's a scientific analysis of these issues, in this way, we can put forward the countermeasures to improve the use effect of self-media platform, and ensure the efficiency of college enrollment propaganda work ${ }^{[4]}$.

\subsection{Low Level of Platform Promotion and Management}

Although many colleges and universities have applied self-media platforms in their recruitment campaigns, But the application level of self-media platform is low, there are still problems in management, the application effect is not good enough. When colleges apply self-media platforms, Not actively developing new features, The functionality on the platform was also not optimized, the function of self-media platform cannot be brought into full play ${ }^{[5]}$. At the same time, college enrollment publicity for self-media platform in the application, Low activity, although many colleges and universities also send copies on the platform, but the activity is low, lacks the interaction with the student, therefore the platform management also becomes the influence self-media platform application effect one big factor.

\subsection{Low Quality of Content Pushed by the Platform}

In the process of applying self-media platform to college enrollment propaganda in the process of recruiting students, because of the low quality of the content, not only can not attract students' attention, will also affect the image of colleges and universities. Many colleges and universities don't know enough about the importance of self-media platform in enrollment promotion, regular parttime job placement, so that the platform copy editors lack enthusiasm, often push some of the lower quality content, the quality of recruitment publicity work has a great impact $^{[6]}$

\section{Application Strategy of Self-media Platform in College Enrollment Publicity in New Period}

The competition for college enrollment is fierce, However, there are many personal needs for students, and the existence of these needs poses a great challenge to the recruitment and publicity work. The traditional self-media platform model has been unable to adapt to the development of contemporary society, more can not meet the actual needs of students, so colleges and universities through refinement, Modern management mode, constantly improve the management effect of self-media platform. The following is how to improve the application effect of the self-media platform college enrollment publicity:

\subsection{Intensify the Promotion of Enrolment from Media Platforms}

Self-media platform can edit and push information accurately in practical application. To enhance the efficiency of information dissemination, and students can also communicate with universities on the platform, understand each other's needs. The promotion of self-media platforms needs to be done through: First, from the media platform of autobiography broadcast. Self-communication capability is a feature of self-media platform, especially in the process of increasing the audience of the platform, communication capacity is also enhanced. Therefore, colleges 
and universities must actively set up the content of the copy, promotion of adaptive media platform. For example, when we post the enrollment information on WeChat, you can set the QR code at the bottom, to facilitate the dissemination of push information, keep abreast of more relevant information ${ }^{[7]}$.

Second, the traditional propaganda platform and materials as carriers. In college enrollment publicity, make good use of the traditional propaganda platform with high attention, such as college pipe network, Set the window from the media platform on the pipe network, let students in the process of vagrant pipe network can click and know the relevant information at any time. It can also include media sites or QR codes in print media such as newspapers and posters, Improve the promotion efficiency of self-media platform.

Third, Make use of the publicity campaign. Many colleges and universities organize enrollment seminars and other activities, and then in the propaganda interaction, integration of media platforms into promotional activities, to enable students to learn about self-media platforms, and timely subscription or attention to college enrollment publicity from the media platform, this will enable students to push more comprehensive, latest information.

\subsection{Enhanced Quality Management of Content from Media Platforms for Recruitment Promotion}

The high activity of self-media platform is due to the high quality of content, and update faster, more attractive to young people, meet the actual needs of young people. Improving the quality of content from media platform, content quality management is required in the following manner: First, reasonable use of platform interactive data. Self-media platform in practice, with two-way interaction, Number of fans through media platforms, activity and evaluation forwarding, can subjectively reflect the quality of self-media platform content. Current Weibo, the WeChat public number and so on are more commonly used self-media platform, with the support of user data analysis, university self-media managers can analyze data, get the user's favorite content, and timely push the relevant information content for the user.

Second, adjust the content push frequency reasonably. Since the media platform content push frequency, will have a great impact on the user's feelings. If the content is pushed less frequently, It's hard for the user to remember the push, Even let the post user forget the relevant content, Failure to achieve publicity; If the content is pushed more frequently, it makes users feel bored, and will soon be drowned out in this huge information, allows users to obtain useful information accurately. So, when colleges and universities manage their own media platforms, we must pay attention to the frequency of content push and push the content for a specific time period to ensure the high efficiency of content push.

Third, pay attention to the change of students. When using the self-media platform for college enrollment publicity, must carry on the prompt understanding and the grasp to the group change, the audience of the platform is generally senior three students and some parents and teachers, But when the college entrance exam is over When students enter college, the audience will decrease. At this time, the role of the college enrollment publicity platform will be weakened, A lot of people cancel their attention to self-media platforms. So college admissions promotion from the media platform managers must be aware of this select content suitable for the audience to push, and often set up some interaction on the platform, to enhance the fun of the media platform, to consolidate the fans, to attract new fans, enhance the value of self-media platform in college enrollment publicity work.

\subsection{Ensure Effective Integration of Student Advocacy from Media Platforms and Traditional Platforms}

It's not desirable to have a single way of recruiting students, so colleges and universities must enrich their propaganda methods, to meet the needs of different audiences So while applying to the media platform, nor abandon traditional platforms. Although the media platform in the new era has played a great role in the recruitment publicity work, But the traditional propaganda platform still has its own value, Enrollment sites, for example, are still important channels of publicity, its audience is also very large. So, colleges and universities in the actual enrollment publicity work, we should combine the media platform with the traditional propaganda platform scientifically, give full play to their strengths, continuously improve the quality and efficiency of college enrollment publicity work. The traditional publicity platform is still one of the main publicities for enrollment, many audiences still choose traditional platforms to learn about the information Therefore, it is necessary to combine self-media and traditional platform reasonably to meet different audiences with different needs and provide multiple channels for the audience to obtain information.

\section{Knots}

In the new era, colleges and universities must keep up 
with the trend of the times when recruiting students. Enhancing the application of self-media platforms, constantly provide the audience with high-quality enrollment publicity content. Although in the use of self-media platforms, there are still shortcomings, but university self-media platform managers must be aware of these deficiencies, and formulate scientific countermeasures to continuously optimize the practical role of self-media platform. At the same time, in the process of using self-media platform, the user's data information should be systematically analyzed, combined with the traditional propaganda platform We will continue to optimize push content, strengthen the maintenance and development of self-media platforms, and enhance the quality and efficiency of college enrollment publicity.

\section{References}

[1] Song Haifang. Research on the Construction of Party Building and Publicity in Colleges and Universities since the Media Age — Taking the WeChat Public Platform of Chinese Classical Dance Department of Beijing Dance Academy as an example [J]. Culture Monthly ,2018(10):150-151.

[2] Bi Li, Su Chang, Sun Ting, et al. Application of Self-media Backstage Data Analysis in Improving the Communication Power of Medical Academic Journals [J]. Shanxi Science and Technology, 2018(04):110-115.
[3] Li Xuerui, Li Qing. Research on advertising marketing strategy of WeChat public number since media era —_ Taking "talent limited youth" as an example [J]. Media Forum, 2018(07):105-106.

[4] Liu Lei, Lu Shijun. A New Way of Ideological and Political Education in Colleges and Universities in the "Self-Media Age"-- Taking WeChat Public Platform as an Example [J].] Economic Research Guide, 2015(16):226-226.

[5] Zhu Jin, Liu Xiaolong, Xue Boxin. Application of self-media platform in the new cultivation mode of "four syndromes in one" for urology graduate students $[\mathrm{J}]$. Chinese Medical Education Technology, 2018(01):41-44.

[6] Ye Zhenglong, Sun Jiechang . On the Inquiry and Thinking about the Application of Self-media to the Teaching of College Curriculum — Taking the Application of Ceramic Technology Materials as an Example[J]. Journal of Jingdezhen College, 2015(05):121-124.

[7] Zeng Jie, Guo Chuxu. Research on the Innovation Path of College Culture Construction and Communication in the Field of Media — Taking Five Universities in South Jiangxi as an Example [J].] Northern Literature: Zhong ,2017(08):176. 